\section{A rare case of migration of a T-tube into the duodenum}

Migration of a biliary stent from the intrahepatic biliary tract into the duodenum is a known complication after endoscopic retrograde cholangiopancreatography (ERCP). The procedure to remove these stents has also been reported in the literature. We report on a case of T-tube migration into the duodenum, and describe the cause of migration and the technique to remove the migrated T-tube. This has particular relevance to cases in which ERCP fails to remove large impacted calculi or when the terminal common bile duct (CBD) is narrow. These patients then undergo surgical removal of CBD stones.

A 35-year-old man with obstructive jaundice due to choledocholithiasis underwent ERCP, which suggested multiple, large CBD stones. Complete clearance was not achieved and therefore papillotomy was performed and a plastic stent was placed. The patient subsequently underwent cholecystectomy with choledocholithotomy. Multiple large stones were extracted during the surgery and a T-tube was placed. The previously placed stent was removed during the surgery. The patient was discharged with the T-tube in situ.

After 2 weeks, T-tube cholangiogram revealed migration of the T-tube into the duodenum ( Fig. 1). The T-tube was removed endoscopically using a sideviewing ERCP scope ( $\mathbf{F i g}$. 2). The patient was discharged the next day.

There are many articles in the literature that report migration of stents into the duodenum and cecum after ERCP $[1,2]$, and there is even a report documenting percutaneous stent migration after ERCP [3]. The present case is the first documentation of T-tube migration into the duodenum. In this case, the T-tube cholangiogram proved to be extremely beneficial, as any attempt to pull the T-tube out percutaneously would have resulted in complications for the patient; the duodenum might have been torn causing bile leakage and the possibility of a vasovagal attack. Migration of the external end of the T-tube into the peritoneal cavity has been reported previously, and was managed endoscopically [4]. In the current case, however, the patient was asymptomatic and the Ttube migration was diagnosed only when T-tube cholangiography was performed. The conclusion from treating this patient was that a wide sphincterotomy can result in T-tube migration into the duodenum. In compliance with the standard recommendation, a T-tube cholangiogram should always be obtained before removing the T-tube. Finally, the migrated T-tube should not be pulled out percutaneously as is usually done, but should be removed safely by an ERCP scope.

Endoscopy_UCTN_Code_CPL_1AK_2AJ

\section{Competing interests: None}

\section{Mohan Achyut Joshi, Minakshi Gadhire, Mansha Singh, Raghav Shrotriya}

Department of General Surgery, Lokmanya Tilak Municipal Medical College and Hospital, Mumbai, India

\section{References}

1 Cerisoli C, Diez J, Giménez M et al. Implantation of migrated biliary stents in the digestive tract. HPB (Oxford) 2003; 5: 180-182

2 Kountouras J, Paroutoglou G, Chatzimavroudis $G$ et al. Migration of plastic biliary stents and endoscopic retrieval: an experience of three referral centers. Surg Laparosc Endosc Percutan Tech 2009; 19: 217-221

3 Joshi MA, Thakur BA, Dhopade TG et al. Silent percutaneous migration of plastic biliary stent through ileum. J Postgrad Med 2009; 55: 196

4 Krishnan A, Ramakrishnan $R$. Endoscopic management of a migrated biliary T-tube. Endoscopy 2011; 43: E325

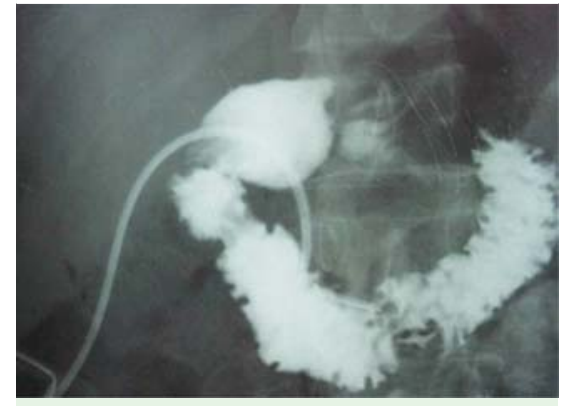

Fig. 1 Postoperative T-tube cholangiogram showing the T-tube in the third part of the duodenum.

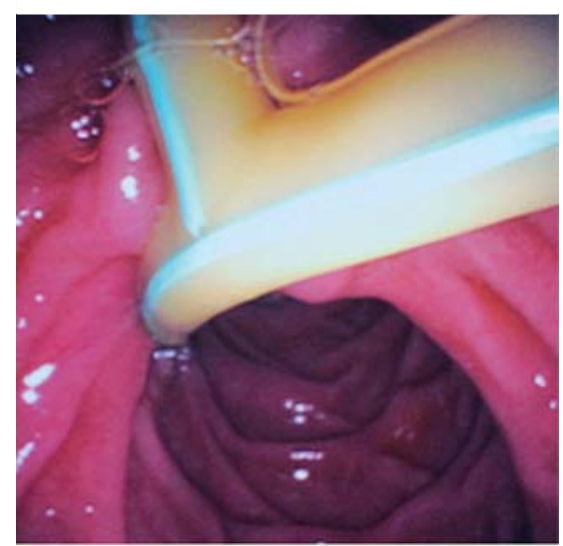

Fig.2 Endoscopic view of the migrated T-tube in the duodenum.

\section{Bibliography}

DOI http://dx.doi.org/

10.1055/s-0034-1364943

Endoscopy 2014; 46: E142

(c) Georg Thieme Verlag KG

Stuttgart · New York

ISSN 0013-726X

\section{Corresponding author}

\section{Mansha Singh, MS}

Department of General Surgery

Lokmanya Tilak Municipal Medical College and Hospital

802, Nisarg Building Pali Hill Bandra

West Mumbai

Maharashtra 400050

India

Fax: +91-22-28506999

singhmansha@gmail.com 